\title{
DISRUPTED LEARNING DURING THE COVID-19 PANDEMIC: COLLABORATING TOGETHER STRENGTHENS OUR EFFORTS
}

\author{
Suzie Bartlett, Cynthia Mullens, Teresa Bradfield \\ and Jean Ross
}

\section{INTRODUCTION}

In this paper three doctoral candidates at New Zealand's Otago Polytechnic and their academic mentor reflect on the impact of the COVID - 19 pandemic on their approach to contextualising, designing and accomplishing their research goals.

Associate Professor Jean Ross is the academic mentor for the three candidates, and all three began their Doctor of Professional Practice (DProfPrac) journeys before the pandemic. Anticipating the disruptive effects of New Zealand's pandemic response (New Zealand Government, 2020), Ross invited each candidate to engage in a conversation about their research plans and progress, and to collaboratively consider how the effects of the pandemic would challenge their DProfPrac journeys.

The three candidates are at different stages within the doctoral programme. A learner involved with the very beginning of this journey (Bradfield) will investigate disruption as a concept from a personal and academic perspective, while completing a review of learning. A reflection in action from a learner collecting data (Mullens) will follow, and a learner who is currently analysing and consolidating data (Bartlett) will conclude the paper. The three learners will be identified below according to the phase of their learning journey as Phase One, Phase Two and Phase Three of the DProfPrac set within the context of, COVID-19 while demonstrating their collaborative actions and encounters.

\section{CONTEXT}

\section{Otago Polytechnic's Doctor of Professional Practice}

The DProfPrac is a work-based qualification which enables candidates to collaborate with their academic mentors to reflect on their previous experiences and learnings which assists them to develop their individual learning agreement before undertaking research that is meaningful and relevant to their professional practice. Candidates create new knowledge for and about New Zealand's workplaces through applied practice and research projects, facilitating the development of their personal and professional practice (Doctor of Professional Practice, 2020). Candidates enrolled in the programme have chosen to research and reflect on areas that are directly related to their everyday practice, and the knowledge gained is personal and meaningful in a way that advances not only their professional but also their the personal self. A reflective process (Phase One) takes concrete occurrences into the realm of values, attitudes, and the ways in which the world is viewed and how it works (Mezirow, 2000). 
Phase Two - the development of a learning agreement - includes an exploration of the candidates' ethnocentric thinking and the lens through which personal and professional narrative have evolved. Phase Three is about the candidates' research processes, and their outcomes and outputs. All three phases relate to collaborating with their academic mentors and DProfPrac candidates.

However, during the COVID-19 pandemic and Alert Level 4 and 3 lockdown in New Zealand candidates have needed to reconsider their approach to their research with their academic mentor which has changed direction for two of the candidates. A brief discussion of COVID-19 is presented below followed by an explanation of collaboration to situate these two concepts with the New Zealand COVID-19 context.

\section{COVID-19}

COVID-19 is caused by a highly infectious coronavirus, first documented in Wuhan, China, in December 2019 (World Health Organisation, 2020), and declared the cause of a global pandemic on 12th of March 2020 (New Zealand Government, 2020). The virus is spread through droplets of saliva or nose discharge. There is no vaccination or cure for COVID-19 at the time of writing. The most effective control measures are quarantine (at national borders where possible), social distancing, and face covering (mask wearing). New Zealand created a national alert level system to manage COVID-19 (ibid), set first at Level 2, which then rose to Level 3 for 48 hours, before a nationwide Level 4 lockdown on March 26th 2020. This level's strict guidelines only allowed individuals to exit their homes for essential services, limited exercise, or if they met essential worker criteria.

The Level 4 lockdown has seen a rapid decrease in the number of cases of COVID-19, and the country moved to Level 3 on April 27th. At the time of writing the country is at Alert Level I, which allows normal day-to-day activities. Our borders are our defence, with restricted access to those entering New Zealand. COVID-19 has changed the way that we interact with others, go about our lives, our work, study and many other parts of our usual daily living. These changes are causing stress and uncertainty, and a significant impact on the mental wellbeing of people within New Zealand (Ministry of Health, 2020).

\section{COLLABORATION}

Groups of individuals working together - collaborating - can extend sharing and reflection, and create new understandings and visions (Gilbert, 2016). Collaborative success depends on six factors: first, trustful teamwork, goal setting and achievements, planned and executed together; second, collective responsibility for vision and goals; third, a clear purpose that captures the vison and goals; fourth, clarity about timelines and deliverables; fifth, open and frequent communication; and sixth, collective inquiry with common goals and meaningful debate. Collaborative working relationships create challenges - individually and collectively - but also enhance debate and broaden horizons. We have all encountered working collaboratively together with our academic mentor and together as DPP candidates, hence this collaborative publication.

\section{PHASE ONE - TERESA BRADFIELD'S REFLECTION}

Phase one of the DProfPrac focusses on reviewing prior learning; identifying the experiences and skills that cumulatively offer the pre-requisite requirements for entry. It is a challenging process, involving personal reflection on practice, developing a deep understanding of my research paradigm.

Offering a perspective on disruption initially seemed a straightforward request. I am at the starting blocks, and my first thoughts were that it should be straightforward. However, as my academic mentor once said "we see the world as we want to, not as it is." Remembering this, I took longer to work on documenting my perspective than 
I had imagined. A realisation is that we are the sum of all of our parts - one cannot write about perspective, or disruption, without considering the meaning of each word and the context in which it is applied.

I thought about the definition of disruption, and settled on the Cambridge Dictionary definition: the action of preventing something, especially a system, process, or event, from continuing as usual or as expected; and the Cambridge definition of perspective, a particular way of considering something (Cambridge Dictionary, 2020)

As a learner, my research paradigm aligns with the qualitative, interpretivist paradigm. Patton (2015) says that qualitative inquiry is about illuminating meanings and how humans engage in meaning making, which in the context of a global pandemic invites me to personally reflect on how I apply my experience as a health professional, how I apply my knowledge of clinical governance and leadership, and what this means for my current doctoral pathway focussed on engagement in clinical governance.

I have thought about Covid-19 with a perspective that enabled me to begin to make sense of what I see emerging around me. As a learner, understanding the immediate pivots required to continue to successfully study, the virtual space, and the lack of social contact, all make sense in this context. It is not a hardship to transition, and personal disruption in this sense is limited, mainly because of time and place in my study programme. Had I been in the data collection phase, I would have viewed the disruption differently - not quite a showstopper, but enough to need a re-plan. Why, you might ask, would that matter? Because my focus is on engagement, connection, relationships and the human condition, my experience of the whole. I would miss the subtlety, the small things that help me make sense of what I see and hear. From a learner perspective disruption is a future possibility in my study design, which one could argue, at this moment, is purely academic.

My next perspective - a systems view, acquired as a health professional - affords me an insider perspective to COVID-19 illuminating the disruption it has caused as it envelopes the globe. Insider research places the researcher within an area of familiar practice. It has benefits - there is common understanding of process and language - and it has disadvantages; it may mean some things are taken for granted, that uncomfortable subjects may be avoided (Costly, 2010).

I have previously researched clinical governance, leadership and organisational culture (Bradfield, 2019), completed pre COVID-19. An illuminating piece of research, it highlighted the importance of relationships based on trust and respect and engagement between governance and clinicians. As I reflect on those findings, I see COVID-19 as the opportunity for clinicians and governors to work together differently, and indeed, we are witnessing significant changes in clinical governance relationships overseas as countries struggle with the clinical demands and ethical dilemmas presented by the overwhelming impact of COVID-19.

There are opportunities for government, governance, health practitioners and academics to become united during the disruption caused by COVID-19. Perhaps this experience will redefine relationships and form fresh perspectives, enabling us to see the world through a different lens, and create greater resilience in our collective community through collaboration.

Finally, there is the personal response to the pandemic threat, and the disruption to our livelihood and wellbeing. Abraham Maslow's (1943) hierarchy of needs came to mind as we entered lockdown. Survival, safety, physiological needs and Maslow's pyramid emerged to me from my past as a student nurse. I guess, from my perspective it was the human component of disruption that brought this to mind. It was perhaps the most illuminating moment in preparation for a new way of living during lockdown, because it reminded me that we plan for a future, but in reality we only have the past and the now. Making sense of the now, being more aware of the now, helps put our life in perspective, but perhaps that is a learning from COVID-19, in our busyness of day to day activities we forget to consider why the now matters. 
COVID-19 is likely to be with us for a very long time; disruption will become a common theme in our lives. Our perspectives will change as we work together throughout the pandemic evolution, and for some of learners that will involve changes of plans, a slowing down, a review of direction of travel. Our relationship with co-learners, and others, will change, and perhaps be strengthened by the adverse situation we all face as we develop new resiliencies and collaborations. We will each attempt to give meaning to what is happening, and in connecting with others, discover new connections.

I conclude with a quote from Patton (2005 p.54), "People in the field may appear more distant than they are. Or closer. Or both at the same time. In every case these appearances are not what's important. Get closer. And closer. To get beyond appearances."

\section{PHASE TWO - CYNTHIA MULLEN'S REFLECTION IN ACTION}

As defined by Schön, reflection in action is the use of the reflective process through experience - learning that captures knowledge and meaning (Schön, 1983).

Currently in the middle of phase two of my DProfPrac journey, with my research approved by Capable NZ's ethics committee (Doctor of Professional Practice, 2020), data collection has become my dominant focus.

Upon reflection, disrupted learning seems redundant in that all learning disrupts some aspect of how we think, view and act within the world around us. With that great gem of wisdom, undertaking the DProfPrac has continued to disrupt multiple aspects of learning for me. I am learning that choosing a project that is entwined with self and work has become a very refining space to occupy. Refining removes impurities from impure metals through the smelting process, therefore increasing value or worth of the metal. Metaphorically speaking the DProfPrac has acted as this refining heat, requiring me to view aspects of my chosen project from angles I have not always wanted to see. Rogoff (1995) refers to this as the concept of participatory appropriation, where individuals change through their involvement in an activity, and through their participation are prepared to handle future situations - a process of becoming.

The year 2020 will be the year of becoming for the global population, refining the way we see ourselves, our humanity, and the world around us. In January 2020, as I completed my first course for the DProfPrac, the exciting second stage of the journey was just beginning. The cataclysmic shift of focus was so sudden, my ethics application was rendered out of date within a 48-hour time frame. Two files with the names pre-pandemic, and post-pandemic ethics application now sit within my hard drive. I have been evolving the concept of this project since 2017 , building relationships with communities and learners to investigate ways of working to develop a slow and compassionate pedagogy to inspire learners to step outside what they know and focus on aspects of global health. Globalisation has rapidly changed every aspect of how we think and view health. As a registered nurse, I have worked, and personally experienced the learning that occurs when working in community health in resource-poor environments. As an educator this became the focal point for inspiring learners to seek out opportunities that would shift their perspective and provide them with an opportunity to engage in a real life context of community health with a global focus.

An important component of my practice as a registered nurse as well as an educator has been the power of community. Delanty (2003) defines community as a powerful idea of belonging in every age, with a reality that consists of persuasive power as the most social aspect of society. This concept of community captures the multiple aspects of teaching and learning, with the realities of practice as a nurse in a global context. My pre-pandemic plan included traveling to a remote community in Vanuatu to complete a Primary Health Care Clinical Placement, working and living in a community to collaborate with community stakeholders and health care workers to find local solutions to health needs. As you can imagine, the logistics of occupational health and safety, travel, and fundraising are an essential component of the viability of any such collaboration and this planning was 
well underway through continued communication with community stakeholders and those learners who were to be involved with this project. Planning, organising, and developing this project had been underway since 2017.

A pivotal point in time was deciding to switch this project into a virtual space. As more information became available and the response of governments struggling to find a systematic approach to management of COVID-19 emerged, the core team involved with planning and facilitating this fieldwork met to discuss our options. It became evident through our discussion that this work could not go forward as originally planned, and community stakeholders and learners were informed of the decision. Many people have worked in collaboration with me during this time to help me shift my focus from what could have been to what can be.

There is a sense of strength in choosing one's own path, and I have learned that leadership is about the proactive approach one takes. Through guidance and knowledge, we strive to meet needs as they change, having the courage to continue to walk in faith that your work will have an impact. Trusting that the process may look different to what you expected, but in the end, isn't that the disruptive process of learning?

\section{PHASE THREE - SUZIE BARTLETT'S REFLECTION ON ACTION}

Where reflection-in-action refers to thinking about what you are doing whilst you are doing it, reflection-on-action refers to the retrospective contemplation of practice undertaken in order to uncover the knowledge used in practical situations, by analysing and interpreting the information recalled (Fitzgerald, 1994) - looking back after the event has occurred, through a cognitive post-mortem. It involves the turning of information into knowledge. This kind of reflection not only enhance knowledge, but also challenges one's theories and concepts (Bolton, 2004).

My data Phase Three collection and thematic analysis are complete and the research process is underway. The excitement of discovering new knowledge that is meaningful and can create change is tangible. Understanding of self and community or perspective is well developed in readiness to defend my research. Writing of the thesis is underway. What I have come to understand throughout the DProfPrac journey is disruption, perspective, reflection in action and reflection on action are present and enduring whether we want them to be or not. This is part of the process, the journey, and the learning. From disruption, resilience develops. From resilience strength develops.

Innovators are told: "Think outside the box." (Patton, 2002) Qualitative scholars tell their students (enlarging on Bradfield's quote above): "Study the box. Observe it. Inside. Outside. From inside to outside, and outside to inside. Where is it? How did it get there? What's around it? Who says it's a box? What do they mean? Why does it matter? Or does it? What is not 'box'? Ask the box questions. Question others about the box. What's the perspective from the inside? From outside? Study diagrams of the box. Find documents related to the box. What does thinking have to do with the box anyway? Understand this box. Study another box. And another. Understand box. Understand. Then you can think inside and outside the box. Perhaps for a while. Until it changes. Until you change. Until the box becomes inside - again. Then start over. Study the box" (p.2).

The COVID-19 pandemic has led to much thinking inside and outside of the box in my professional practice as a nurse educator and as a doctoral learner. The rapidity of the pandemic taking the country to lockdown Alert Level 4 was extraordinary. Undergraduate learners in the Bachelor of Nursing programme went from being immersed in clinical practicum, to being withdrawn from their clinical placements sometimes with minutes notice. Students were in a state of flux with unfinished hours, unfinished papers, uncertainty and heightened levels of anxiety. As a practitioner this meant taking hours and hours of theory normally delivered face to face and converting this to online learning with little notice.

Being an innovator and observing the box from inside and out became our new modus operandi. From being in isolation during the lockdown period, came new comradeship among practitioners as we worked toward a 
common goal to facilitate virtual student learning. This disruption caused much reflection on action. Collection of feedback from learners; thinking of the what next in case we return to lockdown in the future; asking how can we do this more effectively?

As a learner in the DProfPrac, I am currently developing a national framework for tertiary learner mental health and wellbeing. The increased demand for psychological support by students is at times becoming overwhelming for staff, contributing in turn to their own psychological distress. The acuity and complexity of complaints presenting to student support services at Otago Polytechnic and also at an institutional level internationally, is heightened (Storrie, Ahern \& Tuckett, 20I0).

Resilience was one of the three main themes that emerged from my data analysis. Not just taking into account resilience of undergraduate learners and staff, but resilience of courses. Building resilient courses that meet learning outcomes and deliver the required content in an engaging way through online platforms has been new territory. Reflection on action, seeing the box from all angles, has enabled this altered form of teaching and learning to be robust, resilient and of high quality. Teachers have become learners and learners have become teachers. Development of new skills in online delivery have opened new possibilities for future delivery of online courses. Resilience of staff and learners has been tested, the mental health and wellbeing of our people has been challenged.

Pastoral care has been delivered in virtual spaces, with learners asking for this to continue beyond COVID-19. The mental health and wellbeing in an already vulnerable population of tertiary learners has been tested through this pandemic with the restrictions put on personal, social, and learning activity. Staying connected has been key. Now more than ever I am aware that my research is valid and meaningful, as policy and strategy in relation to mental health and wellbeing of learners' needs moves to the forefront of our organisation and nationally throughout our educational sector.

\section{CONCLUSION}

It is important to note four main themes that have emerged throughout this contribution to this article: disruption, reflection, change, and collaboration. Doctoral learners have demonstrated their ability to change course when threat has turned to opportunity. New directions have arisen in research projects taking the doctoral learner in an entirely new direction due to COVID-19.

Reflection in the process of action is evident, and learners identify thinking in a disrupted landscape. Thinking in this space has altered the lens through which learners' view themselves, their projects, and their communities nationally and internationally. Disruption is a theme throughout each learners' experience, making new meaning through inquiry and reflective practice.

These four themes all develop resilience which has emerged as a fifth theme: academic resilience - a learner's capacity to overcome acute or chronic adversities that are seen as major assaults on educational processes (Martin \& Marsh, 2015). Recently, academic resilience has been noted as a factor in ways of coping for tertiary students. Resilience is therefore a key concept for tertiary learners. It enables them to persevere when disruption and change occurs outside their control, to continue an altered path - going left instead of straight ahead if you will.

Resilience helps us make new meaning from complexity and develops us as human beings. The doctoral journey is responsible for not only the creation of new knowledge in our unique practice areas but for development of self and community. We will emerge more resilient, more critical in our thinking, shaped by our own individual journeys to understand our place in the world, and our passion. New connections and collaborative relationships will be forged, and new knowledge will be shared. Collaborating together with the guidance of our academic mentor has strengthened our journey, with a vision which supports all our efforts. 


\section{ACKNOWLEDGMENTS}

Significant thanks go to Dr Malcolm Macpherson who has so elegantly offered an editorial lens over this paper, we thank you wholeheartedly.

Suzie Bartlett RN, Dip Comp Nur, MHEd, PG Cert HEd, AOKNZ National Ambassador is a Principal Lecturer in the School of Nursing at Otago Polytechnic, Dunedin, New Zealand. Suzie completed her Masters degree in Higher Education on the merits of mental health simulation and the use of standardised patients in 2015 and is currently nearing completion of her Doctorate in Professional Practice. Suzie's doctoral research is on tertiary learner mental health and wellbeing and the development of a national framework.

Cynthia Mullens RN, BSN, MPH \& TM is a Doctoral Candidate and a Senior Lecturer in Nursing at Otago Polytechnic, Dunedin, New Zealand. She has worked extensively during her twenty-year career in global health and community development, working across multiple cultures and communities. Aspects of her practice have strengthened her commitment to working towards social and equitable health outcomes, both locally and globally. She has a commitment to develop and implement the Pedagogy of Compassion through global health collaboration with communities and learners.

Teresa Bradfield RN, MProfPrac has lived in New Zealand since 1986. Teresa's career achievements include executive management and professional leadership roles in health and disability. Teresa's MProfPrac explores the relationship between 'Clinical Governance, Organisational Culture, and Leadership'. A current Doctor of Professional Practice candidate, her future study is researching engagement optimisation between clinical governance and governance.

Jean Ross (ㅁ0000-0003-2467-9233) RN, BN, MA Nursing, PhD, FCNA (NZ) is Associate Professor in Nursing at Otago Polytechnic, Dunedin, New Zealand. She has more than 25 years' experience of working with the rural nursing workforce. Jean is the current lead mentor of all three of the DPP candidates presented in this paper. Jean has published two books and numerous journal publications.

Correspondence to: Suzie Bartlett, Otago Polytechnic, Dunedin, New Zealand. Email: suzie.bartlett@op.ac.nz

\section{REFERENCES}

Bolton, G. (200I). Reflective practice: Writing and professional development. Paul Chapman Publishing, London.

Bradfield.T. (n.d). Clinical governance, organisational culture, leadership. https://www.op.ac.nz/industry-and-research/research/opres/ capable-nz/bradfield/

Cambridge Dictionary (2020) Retrieved from https://dictionary.cambridge.org/dictionary/english

Costley, C., Geoffrey, E., \& Paul, G. (2010). Doing work-based research: Approaches to enquiry for insider-researchers. London: SAGE Publications Ltd.

Delanty, G. (2003). Community. London, New York: Routledge.

Doctor of Professional Practice. (2020). Otago Polytechnic, https://www.op.ac.nz/study/business-tourism-and-it/business/doctorof-professional-practicel

Fitzgerald, M. (1994). Theories of reflection for learning. Oxford: Blackwell Scientific.

Gilbert, J. (2016). Leading in collaboration complex education systems. Education Council New Zealand. https://educationcouncil.org. nz/sites/default/files/Five\%20Think\%20pieces.pdf

Martin, A. J., \& Marsh, H., W. (20I5). Academic resilience and academic buoyancy: Multidimensional and hierarchical conceptual framing of causes, correlates and cognate constructs. Oxford Review of Education, 35(3), 353-370.

Maslow, A. H. (1943). A Theory of human motivation. Psychological Review 50(4): 370-96.

Mezirow, J. (2000). Learning as transformation: Critical perspectives on a theory in progress. San Francisco: Jossey-Bass.

Rogoff, B. (1995). Observing sociocultural activity on three planes: participatory appropriation, guided participation, and apprenticeship. In Wertsch, J.V., Del Rio, P., Alvarez, A. (Eds). Sociocultural studies of mind. Cambridge: Cambridge University Press.

Schön, D. (2002). The reflective practitioner: How professionals think in action. Bodmin, Cornwall: Ashgate, Arena.

Storrie, K., Ahern, K., \& Tuckett, A. (20l0). A systematic review: students with mental health problems - a growing problem. International Journal of Nursing Practice, 16, I-6. 